\title{
Infrastructure and the state in science and technology studies
}

Social Studies of Science 2015, Vol. 45(I) 137-145 (C) The Author(s) 2014

Reprints and permissions: sagepub.co.uk/journalsPermissions.nav DOI: $10.1 \mid 77 / 03063$ |27|4537566

sss.sagepub.com

@SAGE

\section{Nicholas J Rowland}

Department of Sociology, The Pennsylvania State University, USA

\section{Jan-Hendrik Passoth}

Institut für Soziologie, Technische Universität Berlin, Germany

Andrew Barry, Material Politics: Disputes along the Pipeline (Oxford: Wiley-Blackwell, 20I3) xiv + 244 pp., $€ 60.00 / € 70,60 / \$ 89.95$ (hbk), $€ 24.99 / € 31,30 / \$ 39.95$ (pbk). ISBN I I I8529 I I I (hbk), III8529I2X (pbk).

Jo Guldi, Roads to Power: Britain Invents the Infrastructure State (Cambridge, MA: Harvard University Press, 20I2), 297 pp., $€ 31.95 / € 32.87 / \$ 37.80$ (hbk). ISBN 0674057597 (hbk).

Allan Mazur, Energy and Electricity in Industrial Nations: The Sociology and Technology of Energy (London: Routledge, 20I3) xvii + 227 pp., $£ 90.00 / € I \mid 4,05 / \$ 155.00$ (hbk), $£ 28.99 / € 37.96 / \$ 48.96$ (pbk). ISBN 04I56344I5 (hbk), ISBN 0415634423 (pbk).

Sara B Pritchard, Confluence: The Nature of Technology and the Remaking of the Rhône (Cambridge, MA: Harvard University Press, 20I I) xvii + 37I pp., £38.95/€40.62/\$47.25 (hbk). ISBN 0674049659 (hbk).

Long-time scholars of science and technology studies (STS) may be surprised to learn that Winner's question - 'do artifacts have politics?' - is not the foundation of contemporary literature on technological infrastructure and the politics of the state. The question was first raised in an article published in Daedalus (Winner, 1980), reprinted in The Social Shaping of Technology (MacKenzie and Wajcman, 1999), and then adapted for Winner's (1986) book; is it now possible that artifacts and infrastructure no longer 'have'

\section{Corresponding author:}

Nicholas J Rowland, Department of Sociology, The Pennsylvania State University, 3000 Ivyside Avenue, E. Raymond Smith Building I28H, Altoona, PA I660I, USA.

Email: njr12@psu.edu 
politics, at least in the way Winner proposed, as an essential quality of nearly any technological design or infrastructural blueprint? What concerns us primarily is not that Winner's work goes under-recognized in the books under review here. Our concern is that it goes un-cited; ours is the discomposing thought that Winner's question is no longer worth raising, not even for the purposes of rejecting or re-directing it. In fairness, however, it might be argued that the death knell for Winner's work was published in 1999 by Woolgar and Cooper. One of Winner's banner examples that artifacts have politics is illustrated in Robert Moses' bridges, which were designed with underpasses so low that buses could not traverse them, thus, restricting poor New Yorkers' access to Long Island beach resorts via public transportation. Claiming to possess a bus schedule for routes passing through those parkway bridges, Woolgar and Cooper (1999) concluded that infrastructural technology sort of 'does' but 'does not [really] have politics' (p. 434). In the same year, Joerges (1999a, 1999b), with his final attempts to wrest some residual use from 'do artifacts have politics?', arrived at much the same conclusion. Likewise, another adage - that 'technology is politics by other means' is also noticeably absent in fresh work on infrastructure. In Science, Technology, and Society: An Encyclopedia, Steve Woolgar's entry 'Perspectives on technology and society' informs readers that

social, political, and other factors can be understood as built into the technology [in previous STS scholarship]. This sense is summarized in the STS tradition by slogans such as 'technology is congealed social relations'; 'technology is politics by other means'; 'technology is action at a distance'; 'technology is society made durable'. (Restivo, 2005: 391; emphasis in original)

To us, that old and much-repeated adage was always intended to be active; in order to understand it, you had to see how politics was actively built into technologies. However, much research has turned the idea into a readymade assumption: something to presume in advance to orient research rather than something to prove through research. The titles under review distance us from the former while getting us a little closer to the latter.

In this essay we review four books: Andrew Barry's (2013) Material Politics, Jo Guldi's (2012) Roads to Power, Allan Mazur's (2013) Energy and Electricity in Industrial Nations, and Sara Pritchard's (2011) Confluence, which are part of a fresh line of research that examines infrastructure and 'the state' from an STS perspective. Specifically, we see these books as an extension of a tradition started by scholars such as Sheila Jasanoff (1990, 2004, 2013), researching the role of science and scientific experts in politics; Chandra Mukerji (1989, 1997, 2009), researching the role of politics and design in engineering state projects; and especially Patrick Carroll (2006, 2012), in his foundational efforts to conceptualize the state in STS terms. From here, we review our books, one by one, and then conclude this review essay by hazarding a few guesses as to where this line of research is headed.

In Material Politics, Barry (2013) introduces readers to a paradox:

... as we are beginning to attend to the importance of materials for political life, the existence of materials has become increasingly bound up with the production of information about their performance, origins and impact. (dust jacket) 
For data, Barry utilizes the massive amount of public information about the $1760-\mathrm{km}$ Baku-Tbilisi-Ceyhan (BTC) pipeline connecting the Caspian Sea and the Mediterranean, evidence that became available after the collapse of the Soviet Union. According to the acknowledgements, the book was born from Barry's (2013: x) selective reading of these materials as well as some 'modest' 'fieldwork along the route of the pipeline'.

Barry opens most chapters by dropping the reader into the thick of things. The first and final chapters are the best specimens in this regard. Chapter 1 opens with a plain description of how, in July 2004, a localized controversy arose between a small village (in the lesser Caucasus) and the International Finance Corporation (laying the pipeline). Villagers believed that the hillside positioning of their homes would eventually collapse due to landslide and thus wanted to relocate. They feared that if the pipeline were to traverse the slope their village rested upon, landslides would, in effect, waste the village away. Geoscientific consultants agreed on one of the two points, determining that while the proper next move for the villagers was to relocate, the pipeline laid as planned in the valley of the slope would not increase the frequency of landslides in the slightest. Did the pipeline present such a threat? And, if so, who would be responsible if it did? Unsurprisingly, a controversy ensued, and we learn from this tiny coincidence of history that material politics is born in such moments. The concluding chapter contains a similarly telling vignette. It involves Barry tracking down craters to see for himself whether or not there is any evidence to support reports that the BTC pipeline had been the target of bombs dropped during the war between Georgia and Russia in August 2008.

The bottom line is that the human, natural, and technological system that is punctualized in pipeline construction is not in and of itself inherently political (no matter what Winner said); as materials and environments are brought together and interact in ways unanticipated by the humans dead-set on controlling them both, material politics emerges.

This is where Barry provides a case lesson in the function of transparency, in this case the voluntary pursuit of transparency as a means to rationally improve the experience of oil companies as they pursue transnational oil pipelines. The basic rationale is simple. Instead of dealing with complaints, usually about environmental concerns (e.g. endangered species) or issues of public interest (e.g. land rights), the firm could offset those concerns. They can front-load concerns as a means of obviating them completely from the process, if only they could be transparent enough and maximize upfront accountability. As Barry (2013) writes, his expectation, which was consistent with the expectations of oil company elites at BP (British Petroleum), was that 'transparency might ... foster informed and rational debate while limiting the scope and intensity of controversy' (p. 182). Such logic is, for nearly anybody under the thumb of accountability measures and measurements, hard to question - that transparency of assessment suffocates the hard discussions rather than engaging or enlivening them. However, transparency has a latent function too, a function that is cause for hope. Barry (2013) enlightens us that

... while limiting the scope and intensity of controversy [is anticipated], this does not occur as anticipated. For as the case of BTC demonstrates, the production of information - in the form of the evolving archive [the host for all matters transparent at BP regarding the BTC] - had the effect of multiplying the surfaces on which disagreements can incubate and flourish. (p. 182) 
What Barry makes nakedly plain is that transparency is really a process of deciding what to make present (i.e. public and transparent) and what to make absent (i.e. neither public nor transparent, but not identified as meaningfully so). Thus, transparency is not a thing; it is the process of showing and telling as well as hiding and obscuring. However, the hope that shines through - and we are generally hopeful about this - is that the real solution is right there, in front of us, if only we know how to look for it. The key is to see the transparency process as a whole. Only when all the transparent bits have been taken together will the absences be apparent. It is from these absences that we might multiply much needed discourse on material politics.

For those active in the field of digital humanities, Guldi is well known for her work on 'Paper Machines', an extension for the popular citation manager Zotero that allows text mining, topic modeling, and geo-spatial visualization of large amounts of text. Roads to Power: Britain Invents the Infrastructure State is an account of the construction, maintenance, and ongoing alteration of British road infrastructure between the early 18th and the mid-19th centuries. Through the artillery of procedures and techniques, maps and papers, measures and measurement devices, roads in Britain changed from being under local control to centralized control and then back again. And like the modes of building roads, 'so swings the pendulum of the attitudes toward the state' (Guldi 2012: 200). Guldi's book opens up with a cast iron bridge over the Birmingham Canal at Galton from 1829; according to the story Guldi presents, 1829 finds Britain in an era of parliamentary roads in which bridges and the macadamized road were the most visible symbols of increased governmental spending.

But the history of British roads is more than merely a story of politics to walk upon. It is every bit the story of acting at a distance (through paperwork and surveys) as it is a story of centralization and control (through commissioning and delegation). In four chapters, Guldi shows how military road making and parliamentary efforts to standardize, organize, monitor and administer road construction changed the institutional set-up of planning and engineering; how the centralizing highway became a political topic in itself that could be and was mobilized for the making of an even greater Britain and for the sake of modernization; how, on the other hand, a movement against these centralized highways emerged that was not only fighting for local and turnpike roads, but also for local forms of governing and against increasing centralized government spending; how, eventually, those new British roads were increasingly used by new types of travelers soldiers, Methodists, and artisans - and infrastructure was built around these mobile communities - inns, stables, and barracks - that created spaces for travelers to meet, but also prevented them from meeting the locals. Britain, during those years, was transformed. That is the message to take away. Much of the transformation was due to the changes in its road infrastructure. The struggle about infrastructure - centralized or localized, made from gravel or made from paper, run by local governments or professionalized engineers - is also a struggle about 'power and its tactics'.

While the book is a detailed account of scientific and technological history, the 'infrastructure state' as a concept, though prominently featured in the book's title, remains implicit most of the time. Where and what is this infrastructure state? Maybe it is the military, building roads nobody else really could use except soldiers; maybe it is the parliament, gaining power by making surveys and by making road builders use tools not 
only for breaking gravel but also for making maps and accounts; maybe it is invoked in the ideology of centralization or in the protests and rallies against it; maybe it is the flow of money and investments; maybe it is the system of highways and toll roads itself. According to Guldi, each item in the list above is true. Is, then, the state its own infrastructure or does it have infrastructure? No doubt, to some scholars, Guldi's lack of specificity is unacceptable, especially regarding a term that supposedly orients the book and is important enough to belong in the title. An alternative reading, and this may be too generous, would view Guldi's text as providing evidence of state multiplicity: the state that we see in Guldi's work is, in Law's words, 'more than one and less than many' but, importantly, is treated as a singularity (Law, 2002: 3). While illustrating state multiplicity was not the purpose of Guldi's book, it is a valid, though implicit, take-away message.

Mazur's Energy and Electricity in Industrial Nations is a resource that scholars at the intersection of energy, environment, and sustainability will use repeatedly. Despite the extensive technical and social detail throughout the book, Mazur's work could be read by college students. Mazur opens the book by stating that " $\mathrm{t}]$ here is no "sociology of energy", which, he claims, "seems odd in view of the central role that energy and electrification play in modern society and politics'. While understandable, this is perhaps overstated. There have been a number of announcements of the arrival of sociology of energy: already in the abstract of an article that appeared in the 1988 Annual Review of Sociology, Rosa et al. wrote, 'This review traces key themes and arguments in the sociology of energy and critically evaluates the literature' (p. 149); in 2000, Simon Guy and Elizabeth Shove published The Sociology of Energy, Buildings and the Environment: Constructing Knowledge, Designing Practice; and the Premières Journées Internationales de Sociologie de l'Energie (First International Colloquium on the Sociology of Energy) was held at Toulouse University in France from 25 to 26 October 2012. There can be only so many declarations that there is no sociology of energy in self-proclaimed works on sociology of energy before authors are no longer permitted to conclude that the sociology of energy has not received sustained scholarly attention.

In the preface, Mazur openly - perhaps unfairly and certainly asymmetrically - wagers with his readers: 'I'll wager that out of 100 nontechnical professionals or politicians, not five know how a piece of coal is converted to electric current, or why that current can toast a slice of bread, must less run a computer'. Mazur pragmatically uses the remainder of the book to, as he sees it, forge something of a pathway away from the all-too-common scenario, as he depicts it, where the bumbling social scientist fails to grasp the technical details while, in the office next door, the clueless engineer cannot comprehend why stalwart humans will not adopt new, more efficient technological objects and designs. Mazur attempts to show that STS, famous for its work on the 'public understanding of science' (and technology), could be used to improve the public understanding of science that we so ardently study. In the end, to read this book is to follow Mazur as if he were a docent in the annex wing of a science museum devoted to energy; he walks you through your lessons like 'Why don't we run out?' [of finite commodities like energy], 'Was the growth of energy and electricity usage in industrial nations due more to population growth or other causes?' and 'Do cities save or waste energy?' We are confident readers will immediately sense the indefatigable patience in Mazur's conversational tone; the book is slow and careful - more tortoise than hare - in avoiding unnecessary jargon, even in chapters that 
STSers will love, such as 'The dynamics of technical controversies'. Along the way, Mazur (2013: 204-205, 204) makes no apologies, adopts a strong stance in all of the matters presented in this book, and ultimately concludes that industrial nations waste unconscionable amounts of energy, 'none more than the United States, [but that] ... it is feasible to cut back without sacrificing quality of life' because the '[b]arriers are not technological as much as sociological' (pp. 204-205). He closes the book with a to-do list for our energy future that is worth reviewing (pp. 208-210). In the end, the book is a unique and valuable intellectual melting pot showing us all what sociology and engineering could be if properly united.

Pritchard's book Confluence is an example of contemporary interdisciplinary scholarship situated between STS and environmental history. The basic narrative of the book is simple, self-evident, and twists conceptual insights into plain empirical issues. In the process of (re)shaping the Rhône since 1945, various groups and ambiguous agencies did what STS scholars claim we are doing all the time: we are not just building technologies into an otherwise pure and unaltered nature, but are engaged in enviro-technical modifications; we are not holding nature and technology apart, but are continuously binding and stitching them together. In seven dense chapters, Pritchard takes readers back into the deep entanglements - or, confluences - of infrastructure design, environmental engineering, and nation building: France's nuclear identity, tensions between Paris and periphery, its post- and neo-colonial situation, its place in Europe's transnational layout - they are all tied together by the flow of the river. They are, though, tied not only by the flow of the river's water, but also by the flow of its politics.

At the core of the narrative is an agency (in the - probably intended - double meaning of the notion): the Compagnie Nationale de Rhône (CNR), a major driver for turning the Rhône into an environmental engine and for building a hydroelectric future for France as a whole. CNR's projects shape not only the river's flow, but also the objectives for reconstructing a post-war France and its increased energy needs. Their 29-km long Canal de Donzère-Mondragonmay is not the first of its kind, but it is one of the most far-reaching transformations toward envisioning and remaking of the Rhône. This is not just because it diverted the water (and helped tame the wild beast that the river was before, a wonderful parable of high modernist civilization domesticating the wild South), but because it helped turn the CNR into a quasi-state agency. It was not the only enviro-technical system and regime (Pritchard's twin notions that serve as heuristic tools for enviro-technical analysis) at work: when EDF (Électricité de France) and CEA (Commissariat à l'Energie Atomique) entered the stage and started envisioning and enacting France's new position in Europe and the world through the use of nuclear energy, the Rhône's shape shifted again: hydroenergy (the high modernist dream of early post-war France), nuclear power (the new France), and agriculture (modernized and industrialized through irrigation and land reform) turned the river into a contested instrument of modernization. This changed again in and after the 1970s, when the local struggles about groundwater and the consequences of remaking the Rhône turned into an ecological and 'light green' (Pritchard, 2011: 211) project. The imagined and literal death of the Rhône as an ecosystem as well as a landscape worth reanimating and protecting shaped and continues to shape the character of the river. 
The book is a contribution to the field not only because of the case it presents and the lessons that both those engaged in environmental politics and those interested in studying politics by other means can learn from it, but also because of the shift that Pritchard promises. In Pritchard's view, STS as a whole has been primarily concerned with science and technology while issues related to nature and the environmental assumed a secondary position. Nature is consequently - and quite ironically - naturalized. A necessary correction would be to, rather than reject it as a hollow concept, add it again to the arsenal of machineries that are studied by STS: that is what enviro-technical analysis is aiming at. Pritchard shows readers what such an analysis looks like.

In the end, we agree: the book might have been better if only Pritchard had not picked the most prestigious university publisher in America. The Harvard style requires that all notations be endnotes packed away at the end of the book so that these notes do not muddy up the prose. In a book about rivers, form and functions could coalesce if only the footnotes could flow alongside the text. Her footnotes - when she is not dumping a laundry list of citations - include fascinating and insightful commentary.

What lies ahead for this line of inquiry? We anticipate three directions, and our leadoff points are neatly found in the books we reviewed. First, conceptual developments at the intersection of STS and the state: Guldi's idea of the 'infrastructure state' is a step in this direction. With a perspective on politics where 'to be political in this era is to raise questions about how the state works', Guldi sets us on a path toward the infrastructure state, sensitizing readers to government activities that 'design the flows of bodies, information, and goods' (Guldi 2012: 3-4). But the book is not exactly a model for how to develop a rich concept. The 'infrastructure state' is imprecise at best, and, depending on one's expectations, suffers from a troubling lack of internal consistency. On balance, however, it is common practice in research on the state for scholars to coin new concepts that prominently feature the term 'state' with little reference to the broader literature on state theory. We illustrate our claim with a hypothetical example: if a historical account were to be written about how elite actors in government agencies increasingly adopted planning techniques over the past half-century in order to prepare themselves for hypothetical future contingencies, then it would not be uncommon at this point for a scholar to construct a new concept according to the strict formula of '[select key term] state': 'planning state', 'hypothetical state', and 'future state', or maybe even 'contingency state', are likely candidates in this instance. State activity related to [select key term] becomes the definition of the self-referential term. Such a concept could be developed without reference to the broader literature from state theory and yet constitute a 'contribution' to it. While we openly invite scholars in STS to manufacture concepts according to the standard recipe, there is another direction. We can make a classic STS move: treat state theory the way we treat other scientific theories and treat state theorists the way we treat other scientists. Our hypothetical example hints, if clumsily, at some of the contours and rules for concept construction among scholars interested in matters of state. Second, these books bring an STS perspective to disciplinary areas with a long history of concern over questions of state. In this case, Pritchard's background in history and Barry's background in geography revitalize the role of the state in STS. We fully expect that as our ideas and attitudes in STS are brought to bear on conceptual and empirical concerns from outside of STS by being applied to 'new' questions, our ideas will also be transformed. 
Likewise, by adopting an STS perspective in research even tangentially about the state, state theory will also slowly change in response. The long-term impact of the books under review in this essay remains to be seen, but we anticipate they mark the beginning of a sustained interest in the state by multiple scholars in STS. Studying how STS changes how the state is conceptualized would be a project worth undertaking. Third, these books are policy relevant. By integrating the sociological and technological relevance of state infrastructure, we anticipate that policy-makers and policy researchers will no doubt walk away from these books with a more socio-technical view of the state and, perhaps, a more nuanced understanding of what is at stake when we say that infrastructure is 'political'. Mazur's book and previous work stand as a monument to this potential. Advancing the social and technical understanding of infrastructure without requiring the primacy of either, Mazur painstakingly avoids the lame tar pit of 'social determinism versus technological determinism' that so side-tracked and distracted STS scholars over the past decades.

We will end where we began, with Winner. Because Moses' bridges are canonical in STS and iconic of the old adage that 'technology has politics', it would have been a welcome favor for any one of these texts to have been positioned - either conceptually or empirically - in the context of Winner's (1986) well-known work, even if only a little. The distinctive advantages of a shift toward seeing the state through infrastructure and seeing the state in infrastructure could have been identified and clarified for a whole host of STS scholars unfamiliar with the state and state theory or the important distinction between old definitions of technology and new approaches to infrastructure. Emphasis on state infrastructure also aids scholars in obviating the old dead end of pitting social determinism against technological determinism in their work, while emphasis on politics provides ample opportunity to raise ethical and moral concerns. It was Winner (1986, 1993), after all - seeming far less irrelevant now - who strongly urged scholars in STS to study politics and avoid any form of determinism in the process, advice that neatly summarizes the approach utilized in all four books under review.

\section{References}

Barry A (2013) Material Politics: Disputes along the Pipeline. Oxford: Wiley-Blackwell.

Carroll P (2006) Science, Culture, and Modern State Formation. Berkeley, CA: University of California Press.

Carroll P (2012) Water and technoscientific state formation in California. Social Studies of Science 42(4): 489-516.

Guldi J (2012) Roads to Power: Britain Invents the Infrastructure State. Cambridge, MA: Harvard University Press.

Guy S and Shove E (2000) The Sociology of Energy, Buildings and the Environment: Constructing Knowledge, Designing Practice. London and New York: Routledge.

Jasanoff S (1990) The Fifth Branch: Science Advisers as Policymakers. Cambridge, MA: Harvard University Press.

Jasanoff S (ed.) (2004) States of Knowledge: The Co-Production of Science and Social Order. London: Routledge.

Jasanoff S (2013) Science and Public Reason. London and New York: Routledge.

Joerges B (1999a) Do politics have artefacts? Social Studies of Science 29(3): 411-431. 
Joerges B (1999b) Scams cannot be busted: Reply to Woolgar \& Cooper. Social Studies of Science 29(3): 450-457.

Law J (2002) Aircraft Stories: Decentering the Object in Technoscience. Durham, NC and London: Duke University Press.

MacKenzie D and Wajcman J (eds) (1999) The Social Shaping of Technology. Buckingham: Open University Press.

Mazur A (2013) Energy and Electricity in Industrial Nations: The Sociology and Technology of Energy. London: Routledge.

Mukerji C (1989) A Fragile Power: Scientists and the State. Princeton, NJ: Princeton University Press.

Mukerji C (1997) Territorial Ambitions and the Gardens of Versailles. Cambridge and New York: Cambridge University Press.

Mukerji C (2009) Impossible Engineering: Technology and Territoriality on the Canal Du Midi. Princeton, NJ: Princeton University Press.

Pritchard SB (2011) Confluence: The Nature of Technology and the Remaking of the Rhone. Cambridge, MA: Harvard University Press.

Restivo SP (ed.) (2005) Science, Technology, and Society: An Encyclopedia. Oxford: Oxford University Press.

Rosa EA, Machlis GE and Keating KM (1988) Energy and society. Annual Review of Sociology 14(1): 149-172.

Winner L (1980) Do artifacts have politics? Daedalus 109(1): 121-136.

Winner L (1986) The Whale and the Reactor: A Search for Limits in an Age of High Technology. Chicago, IL: The University of Chicago Press.

Winner L (1993) Upon opening the black box and finding it empty: Social constructivism and the philosophy of technology. Science, Technology \& Human Values 18(3): 362-378.

Woolgar S and Cooper G (1999) Do artefacts have ambivalence? Moses' bridges, Winner's bridges and other urban legends in S\&TS. Social Studies of Science 29(3): 433-449.

\section{Author biographies}

Nicholas J Rowland is an Associate Professor of Sociology and Science and Technology Studies at the Pennsylvania State University. He connects sociological theory and science and technology studies by working on problems of social structure and infrastructures, human and nonhuman agency, and discourse and material culture. He is interested in state theory, the performativity of politics, and actor-network theory. He writes for the blog 'Installing Order'.

Jan-Hendrik Passoth is a Postdoctoral Fellow at Technische Universität Berlin. He also connects sociological theory and science and technology studies by working on problems of social structure and infrastructures, human and nonhuman agency, and discourse and material culture. He is also interested in state theory, the performativity of politics, and actor-network theory. He also writes for the blog 'Installing Order'. 